\title{
Peptic disease in elderly patients
}

\author{
Neda Khaghan MD, Peter R Holt MD
}

\begin{abstract}
N Khaghan, PR Holt. Peptic disease in elderly patients. Can J Gastroenterol 2000;14(11):922-928. The increase in life expectancy demands that more attention be given to gastrointestinal problems, such as peptic ulcer disease, in elderly people. This review summarizes many of the physiological changes that have a role in peptic ulcer disease in elderly patients. How Helicobacter pylori infection modifies the course of peptic disease is also reviewed. The clinical presentation of peptic diseases often differs in elderly people, and atypical symptoms are common. Accurate diagnosis requires aggressive endoscopic evaluation. Treatment regimens using $\mathrm{H}_{2}$ receptor antagonists, proton pump inhibitors and regimens to eradicate $H$ pylori may also need to be altered in elderly patients.
\end{abstract}

Key Words: Elderly people; Helicobacter pylori; Peptic ulcer

\section{L'ulcère gastro-duodénal chez les patients âgés}

RÉSUMÉ : L'augmentation de l'espérance de vie exige qu'une attention plus grande soit portée aux troubles gastro-intestinaux, par exemple l'ulcère gastro-duodénal, chez les personnes âgées. Le présent article donne un résumé d'un bon nombre de changements physiologiques qui jouent un rôle dans l'ulcère gastro-duodénal chez les patients âgés. On y traite aussi de l'incidence des infections à Helicobacter pylori sur l'évolution de la maladie. Le tableau clinique diffère souvent chez les personnes âgées, et les symptômes atypiques ne sont pas rares. La pose d'un diagnostic précis requiert une évaluation endoscopique minutieuse. Il est également parfois nécessaire de modifier les traitements composés d'antagonistes des récepteurs $\mathrm{H}_{2}$ ou d'inhibiteurs de la pompe à protons et les traitements visant à éradiquer $H$. pylori chez les patients âgés.
$\mathrm{R}$ ecent advances in public health and medical care technologies have prolonged the average life span throughout the world. However, this prolonged life span has been accompanied by a higher incidence of chronic diseases in elderly people. Gastrointestinal diseases play a significant role in such chronic illness. As part of this problem, peptic ulcer disease has become a major cause of morbidity and mortality in elderly patients.

In 1991, McCarthy (1) estimated that 25\% of all admissions to hospitals and $20 \%$ of all deaths in the United States were due to gastrointestinal disease. Of the deaths from gastrointestinal disease, one-fifth were due to peptic disease of the stomach and duodenum. Many authors in the Western world over the past two decades have clearly shown that the first diagnosis of peptic ulcer disease and admissions to hospital for complications of peptic ulcer disease occur almost entirely in individuals over the age of 65 years $(2-4)$. Thus, peptic ulcer disease is a disease of elderly men and women, and no longer mainly a disease of young men, as was the case in the 1940s and 1950s.

\section{PATHOPHYSIOLOGY}

A wide range of physiological changes are thought to be associated with the process of aging, including changes in the organs of the gastrointestinal tract. In previous reviews, such effects as decreases in motility, and in gastric, pancreatic, biliary or intestinal secretions, and changes in absorptive capacity have been described. More careful analyses of the physiological effects of aging that excluded the influence of disease resulted in a major reconsideration of what can be attributed to physiological changes as a part of the process of aging.

Table 1 summarizes the major issues surrounding peptic diseases in elderly patients. The following are important: the role of Helicobacter pylori infection in altering the control of gastric acid secretion and in determining the incidence and course of peptic disease in older patients; crucial differences in the clinical picture of older patients with peptic disease; the issue of whether the evaluation and the diagnostic approaches that are usually used in younger patients should differ when considering peptic disease in elderly patients; and

This mini-review was prepared from a presentation made at the World Congress of Gastroenterology, Vienna, Austria, September 6 to 11,1998 Gastrointestinal Division, Department of Medicine, St Luke's/Roosevelt Hospital Center, Columbia University, New York, New York, USA

Correspondence and reprints: Dr Peter Holt, Gastroenterology Division, St Luke's/Roosevelt Hospital Center, Amsterdam Avenue at 114th Street,

New York, New York 10025, USA. Telephone 212-523-3680, fax 212-523-3683, e-mail pholt@slrhc.org

Received for publication August 17, 1999. Accepted September 7, 1999 
TABLE 1

Major issues concerning elderly patients with peptic disease

Changes in gastric acid and pepsin secretion

Changes related to esophageal or gastric motility

The role of Helicobacter pylori infection

Difference in clinical practice

Whether evaluation and diagnostic approaches should differ

Whether treatment should differ

whether treatment options should be altered because a patient is over the age of 65 years (Table 2).

Until recently, it was generally believed that gastric acid secretion declined with advancing age. For example, Baron (5) described a decrease in basal secretion and peak acid output after histamine stimulation with increasing age. This study, however, used 30 years as the age to divide a small number of young and older subjects. More recent studies from the United States and elsewhere reported that basal and stimulated gastric hydrogen ion secretions did not fall if patients with atrophic gastritis and $H$ pylori infection were excluded (6-8). Most of these studies did not include sufficient numbers of volunteers older than 65 years of age. A more comprehensive prospective study that included 22 subjects older than 65 years of age found no significant effect of age on gastric acid secretion after adjusting for the influence of atrophic gastritis and smoking (9). Serum gastrin levels were similar at all age groups but became elevated in the presence of atrophic gastritis. However, pepsin output was significantly depressed in older subjects in this study. A study in rats up to 24 months of age demonstrated a reduction in basal and gastrin-stimulated acid output, and lower serum and antral gastrin concentrations in older animals (10). A recent study in Sprague-Dawley rats between the ages of seven and 90 weeks suggested that gastrin receptor mRNA was markedly higher in 65- and 90-week-old rats than in younger animals (11). The causes and consequences of these changes are unclear.

Further data showing that acid secretion is maintained in old age came from a study using a noninvasive quininium resin method, which distinguishes acid secretion above and below $\mathrm{pH}$ 3.5. In this study, basal secretion was found to be below 3.5 in nearly $90 \%$ of 248 elderly volunteers (12). Subjects with consistent hyposecretion usually showed serological evidence of atrophic gastritis. In young and elderly Japanese volunteers, gastric acid secretion was studied both in the 1970s and in the 1990s, showing greater acid secretion in the young and elderly individuals over these two decades in both $\mathrm{H}$ pylori-positive and -negative subjects (13). This study suggested that elderly Japanese people had lower basal and maximal acid secretion than younger individuals.

It is well recognized that defense mechanisms play a major role in limiting the initiation, progress and healing of peptic ulcers. Gastric and duodenal bicarbonate secretion is an important factor that helps to limit the amount of luminal acid that traverses the mucin layer covering the mucosa. Limited
TABLE 2

Physiological changes with age

\begin{tabular}{l} 
Aggressive factors \\
Gastric hydrogen ion secretion \\
Defense mechanisms \\
Bicarbonate secretion \\
Mucin production \\
Prostaglandin concentration \\
Blood flow \\
Adaptation to injury \\
\hline
\end{tabular}

studies in rodents $(14,15)$ and in humans (16) have suggested that bicarbonate secretion may be lower in older animals and humans than in young animals and humans. The effect of injury on such bicarbonate secretion has not been studied. The secretion of mucopolysaccharides provides an important barrier to acid-induced injury of the stomach. There have been relatively few studies of changes in mucin secretion as a function of age (17), nor has there been any systematic evaluation of changes in hydrogen ion transfer through the mucin layer. Furthermore, studies by Dial and Lichtenberger (18) indicating the importance of the hydrophobic properties of the gastric mucosa in protecting gastric epithelial cells have not focused on changes that might occur during the aging process.

Cryer et al $(19,20)$ evaluated changes in prostaglandin (PG) concentrations in the gastroduodenal mucosa of animals and humans, as well as the PG responses of the mucosa to injury. These results have been confirmed by others (21). These studies have pointed to lower concentrations of $\mathrm{PGE}_{2}$ and $\mathrm{PGF}_{\alpha}$ in the fundus and antrum of the stomach as well as in the duodenum of elderly subjects (aged 56 to 81 years). Furthermore, studies of the effect of stimulants that injure the mucosa upon PG production also suggest that the response is impaired as a function of age (22). Recent findings that very small doses of acetylsalicylic acid (ASA) reduce PG concentrations of the stomach dramatically raise the question of whether some of the previous results of PG concentration may have been due to subjects taking intermittent salicylates (23). All of these data imply that these individuals have a relatively deficient defense mechanism associated with PG secretion.

Changes in blood flow have also been demonstrated to occur as a function of age. Arteriosclerotic vascular changes are almost universally present in elderly people, but their impact on gastrointestinal mucosal blood flow has not been demonstrated to be important. On the other hand, limited studies have suggested that mucosal blood flow may be lower in older animals than in their younger counterparts $(24,25)$. One group of investigators who studied this problem using taurocholate to increase back diffusion of acid concluded that increased injury in older rats was due to impaired blood supply to the stomach because of a defect in capsaicin-sensitive sensory neurons (26).

An important way to understand changes in physiology as 
a function of age is to examine the coordinated effect of injury to the stomach. Such studies can examine the initial extent of injury that is caused by a uniform or standard injurious agent, the subsequent overall healing rate of such injuries or some of the individual steps during the healing process, such as restitution of injured surface or proliferation of epithelial cells. Studies in organs other than those in the gastrointestinal tract have demonstrated defects in the rate of repair of experimental injuries.

Several studies have not shown an increase in ulcer size after application of injurious agents in older rodents compared with younger rodents $(27,28)$. Gastric ulceration induced by acetic acid applied either to the serosa or to the mucosa showed no consistent differences in ulcer size or in ulcer healing in Sprague-Dawley rats aged two to three months, 11 to 12 months or 23 to 24 months (29). In this study, even the administration of indomethacin failed to alter the healing rate of older animals any more than in the younger animals (29). Similarly, Tsukimi and Okabe (28) showed no changes in the healing of gastric ulcers in older rats.

Hypertonic saline application to the stomach was shown to induce more gastric damage in aging rats than in young rats (30). However, studies of acute ASA-induced gastric injury have found conflicting results in animals $(31,32)$. Investigators using cold restraint-induced stress ulcerations also have reported variable results $(33,34)$. Differing injurious agents may have variable effects in different strains of animals.

Because of these differences, it is pertinent to examine some of the individual steps that are associated with prevention of gastric ulceration or accompany effective healing of such ulcers once produced. Epithelial repair after superficial injury is called restitution, a process that takes place immediately after injury and involves cell migration over the injured area. Several peptides are involved, including epidermal growth factor, acidic and basic fibroblast growth factor, cytokines and trefoil peptides. No studies have specifically focused on this process in the gastric mucosa of aging animals.

Majumdar et al (35) performed a series of studies to characterize differences in gastric proliferation and responses to injury in Fisher 344 rats studied between the ages of four and 24 months. This group described an increase in mucosal proliferation in the older animals accompanied by a rise in mucosal membrane tyrosine kinase activity (35) and in other phosphotyrosine proteins (36), including pp60 c-src (37). Basal levels of the mRNA for epidermal growth factor receptor (EGFR) and of EGFR-ligand transforming growth factoralpha were higher in the gastric mucosa of older rats (38). The delay in epithelial restitution that occurs after $2 \mathrm{M}$ sodium chloride-induced gastric injury was accompanied by impairment in the response of EGFR in aging rats compared with that in their younger counterparts $(38,39)$. Delayed proliferation was also associated with reduced tyrosine kinase activity (40).

A reduced proliferative response following injury in older animals has been confirmed by several other investigators
$(30,41)$, in contrast with observations showing a high rate of cell proliferation in aging rats under basal conditions $(28,42,43)$.

Although it is generally believed that esophageal transit and gastric emptying are affected by age, the data do not support this prejudice. The majority of studies that have suggested that motor function is deranged have included individuals with diseases that alter esophageal and gastric motility such as diabetes and neuromuscular disorders. Tertiary contraction of the esophagus is much more common in elderly persons than in young persons, yet this represents a radiological entity without physiological consequences (44). Gastroesophageal reflux occurs more commonly (45). Furthermore, achlorhydria, when it is present due to atrophic gastritis, is well known to be associated with delayed gastric emptying of solids. However, there is some suggestion that the emptying of liquids may be slightly slower because of greater relaxation of the body of the stomach. This function is known to be controlled by the vagus nerve (46). It should also be remembered that many elderly individuals take medications that are associated with anticholinergic actions, which may affect the emptying of both the esophagus and the stomach.

\section{CLINICAL MANIFESTATIONS}

Clinical manifestations of peptic disease differ between elderly and young patients. The classical symptoms of peptic disease may be absent, atypical and often nonspecific in elderly patients (47). Older patients often suffer from other serious medical conditions such as diabetes, as well as from disabilities such as the neurological sequelae from cerebrovascular accidents, which may alter or diminish the symptoms of peptic diseases (47). Even physical signs such as abdominal guarding and rebound can be less prominent in elderly patients because of such coexisting disease, previous surgery or current drugs, including anti-inflammatory medications or corticosteroids. A dramatic example of differences in the clinical picture in elderly patients is seen with acute gastroduodenal perforation, in which the signs of chemical peritonitis resulting from the action of gastric contents may be absent when the patient is hypochlorhydric (48).

The initial symptoms of elderly patients with duodenal or gastric ulcers are often vague and nonspecific (49). Patients present more frequently with anorexia, weight loss, dyspepsia or complications of ulcers such as bleeding, perforation or anemia (Table 3). Abdominal pain occurs less frequently in older patients with peptic ulcers than in younger control subjects (50), and may be absent in as many as one-third of elderly patients who present with bleeding ulcers and in more than half of patients using nonsteroidal anti-inflammatory drugs (NSAIDs) (50).

Gastrointestinal bleeding is a common first manifestation of peptic ulcer disease in the older patient. As a result, these patients may come to medical attention because of systemic manifestation of subacute or chronic blood loss such as shortness of breath, chest pain or loss of consciousness. Thirty-five per cent to $45 \%$ of all cases of active upper gas- 
TABLE 3

Age-related differences in peptic ulcer presentation

\begin{tabular}{ll}
\hline Elderly patients & Younger patients \\
\hline Anorexia & Abdominal Pain \\
Weight loss & Dyspepsia \\
Gastrointestinal bleeding & Gastrointestinal bleeding \\
Dyspepsia & Anemia \\
Perforation & \\
Anemia & \\
\hline
\end{tabular}

trointestinal hemorrhage occur in patients older than 60 years of age; half of these cases are caused by peptic ulcer disease (51). Other causes of upper gastrointestinal hemorrhage in elderly patients are shown in Table 4. Bleeding from any cause in an elderly patient, however, may be aggravated by the concomitant use of anticoagulant drugs (such as coumadin or heparin) or antiplatelet agents (such as ticlopidine, and ASA and other NSAIDs).

Peptic ulcer disease: Gastric ulcer disease is considered principally a disease of advanced age because it is found more commonly in elderly than in young patients. Gastric ulcers in older patients tend to be large and occur with greater propensity higher in the stomach (50). The majority of nonNSAID-associated gastric ulcers in such patients are found high on the lesser curve; therefore, special attention should be paid to examination of the fundus during endoscopy. Many previous studies have suggested specific factors that may be very important in the development of gastric ulcers in elderly patients, including the use of ASA and other NSAIDs, the rising prevalence of gastritis due to $H$ pylori infection with advanced age and the high prevalence of smoking (52).

Giant gastric ulcers, defined as ulcers larger than $2.5 \mathrm{~cm}$ in diameter, also occur more frequently in elderly patients. The peak incidence occurs from 60 to 70 years of age in men and from 70 to 80 years of age in women. These ulcers usually are benign but often mimic the clinical features of gastric cancer. About one-half of giant gastric ulcers present clinically as an acute or chronic bleed. In one study, the mortality rate from bleeding of giant gastric ulcers was as high as 37\% (53), suggesting that early surgical intervention may be warranted. On the other hand, the perforation rate in these patients has been quoted to be as low as 5\% (53).

Gastroesophageal reflux: Gastroesophageal reflux is more common than peptic ulcer disease in both elderly and younger patients. The increased incidence of gastroesophageal reflux disease (GERD) in older patients may be due to the decrease in amplitude of esophageal peristalsis and delayed acid clearance from the esophagus, the increased incidence of sliding type hiatus hernia and the reduction in salivary bicarbonate response to esophageal acid exposure (54). Many medications may also decrease the lower esophageal sphincter pressure and thus make elderly patients more prone to GERD. When heartburn and acid regurgitation are predomi-
TABLE 4

Causes of upper gastrointestinal bleeding in elderly patients

\begin{tabular}{ll}
\hline Gastric ulcer & Esophageal or gastric varices \\
Duodenal ulcer & Mallory-Weiss tear \\
Pyloric channel ulcer & Gastric carcinoma \\
Gastritis & Aorta-enteric fistula \\
Esophagitis & Mycotic aneurysm \\
Duodenitis & Dieulafoy lesion \\
\hline
\end{tabular}

TABLE 5

Methods of testing for Helicobacter pylori

Histology of biopsy samples
Culture of biopsy tissue or gastric contents
CLO testing
Urea breath testing
Serology for of immunoglobulin A and G antibodies to $\mathrm{H}$ pylori

nant symptoms, they can be regarded as highly specific indicators of reflux, but when they are present together with other dyspeptic symptoms, reflux cannot be diagnosed reliably (55). Retrosternal pain occurs much less commonly in elderly than in young patients. Vomiting and anorexia are encountered more often in elderly patients with reflux than in young patients with reflux, and are more frequently described than heartburn (56). GERD is more difficult to diagnose in elderly patients because of increased pain tolerance and the increased gastric $\mathrm{pH}$ that may accompany atrophic gastritis. Symptoms may be attributed to other underlying diseases such as coronary artery disease (57). Because symptoms are frequently so atypical, more intensive investigation in elderly individuals is often required to obtain a specific diagnosis.

$\mathrm{H}$ pylori: It has long been recognized that there is an association among $\mathrm{H}$ pylori, gastritis and peptic ulcer disease. Antibodies to $H$ pylori infection are found in over $50 \%$ of people in developed countries who are older than 60 years of age (58). In one study, the prevalence was found to approach $90 \%$ in patients over the age of 60 years (59). In elderly patients, $H$ pylori infection is usually the cause of gastritis. The most important cause of $\mathrm{H}$ pylori-negative gastritis appears to be overt or covert NSAID ingestion (60).

Several methods are available to detect the presence of $H$ pylori infection, including urease testing of antral biopsy samples (CLO test), culture of gastric biopsy tissue or gastric contents, by ${ }^{13}$ carbon or ${ }^{14}$ carbon urea breath testing, or by the presence of serological markers of immunoglobulin (Ig) $\mathrm{A}$ and IgG antibodies (Table 5). With the CLO test, pieces of gastric biopsy tissue are placed into a solution containing urea with the formation of ammonium hydroxide, which, in the presence of a $\mathrm{pH}$ indicator, turns the sample red. It is important to recognize that our laboratory has found this test to be relatively insensitive in elderly patients (61). The urea breath test for the detection of urease activity involves oral 
administration of ${ }^{13}$ carbon- or ${ }^{14}$ carbon-labelled urea, which is converted by bacterial urease to ${ }^{13}$ carbon dioxide or ${ }^{14}$ carbon dioxide, is absorbed and is then eliminated in the breath, where the labelled carbon dioxide can be detected and measured. Chronic $H$ pylori infection elicits local and systemic immunological responses, leading to the production of $\operatorname{IgA}$ and $\operatorname{IgG}$ antibodies. Testing of serum IgG level only is preferred because this antibody is a more accurate reflection of current infection status (62). Detection of IgG antibodies is not influenced by the patchy distribution of the organism in the stomach, which may occur in elderly patients.

\section{EVALUATION}

Initial tests for patients with peptic symptoms include esophagogastroduodenoscopy and upper gastroduodenal barium study. Endoscopy has been shown to be more accurate than barium studies in the diagnosis of peptic diseases in elderly patients, just as in young patients. Endoscopy is well tolerated and safe, even in very old patients (63). Caution is warranted during sedation in elderly patients, as in younger patients with cardiovascular or pulmonary diseases, and monitoring of oxygen saturation is mandatory. In elderly patients, barium studies can be used to evaluate some upper gastrointestinal complaints if endoscopy is contraindicated because of medical conditions that make sedation dangerous, such as a recent myocardial infarction.

At all ages, the advantages of endoscopy include the ability to take mucosal biopsies for the diagnosis of $\mathrm{H}$ pylori, and to determine the pathology of gastric ulcers and the ability to visualize directly esophagitis and duodenitis. Most patients prefer endoscopy to barium radiology (64), especially elderly patients who are frail and have difficulty moving around.

Evaluation of elderly patients with gastrointestinal bleeding should include tests for altered coagulation, aspiration of stomach contents and a diagnostic test such as esophagogastroduodenoscopy. A lesion can be confirmed as the source of bleeding by endoscopic examination if there is active bleeding or stigmata of recent bleeding, such as a visible vessel or a clot in the ulcer. Identification of the source of bleeding can provide prognostic information and determine the course of therapy. The prognosis also is determined by transfusion requirements and the presence of concurrent illnesses.

\section{TREATMENT}

Early recognition and precise diagnosis are crucial to provide effective treatment of elderly patients with peptic ulcer disease. The failure to diagnose peptic disease rapidly complicates timely therapy. Patients of all ages with peptic ulcer disease should be advised to stop smoking, eliminate alcoholic beverages on an empty stomach and eat regular meals.

If $H$ pylori is diagnosed, this infection should be treated in all patients with a peptic ulcer. If $\mathrm{H}$ pylori is not eradicated by the initial treatment regimen, patients need to be retreated one to two months later because eradication of $H$ pylori has been shown to reduce the rate of peptic ulcer relapse markedly. The most common reason for $\mathrm{H}$ pylori treatment failure is noncompliance, which occurs frequently in the elderly population. Therefore, the simpler the regimen and the shorter the length of treatment the better the results. The newer regimens that include omeprazole, amoxycillin, and metronidazole or clarithromycin for 10 days are as effective as and better tolerated than earlier triple therapy regimens that included colloidal bismuth and required two to three weeks of treatment.

If the patient has no evidence of $H$ pylori infection and is consuming NSAIDs, it is important for the patient to either stop taking the NSAID completely or switch to lower doses of the NSAID. This approach is often difficult in elderly patients with chronic arthritis. NSAIDs induce peptic ulceration predominately because of inhibition of gastroduodenal PG synthesis so that patients may alternatively be treated with a new class of anti-inflammatory drugs that inhibit the cyclo-oxygenase (COX) 2 pathway and have little effect on gastric $\mathrm{PG}$ concentrations.

Mortality from upper gastrointestinal bleeding has remained unchanged, despite the widespread diagnostic and therapeutic use of endoscopy and improved methods of resuscitation. The main reason is that most upper gastrointestinal bleeds occur in elderly patients and that more than $80 \%$ to $90 \%$ of the mortality occurs in this age group. A major reason for the frequency of bleeding episodes in elderly patients is the widespread use of NSAIDs for the treatment of arthritis. Therefore, it is hoped that newer anti-arthritis medications such as the COX2 inhibitors that cause less gastric or duodenal ulceration might lower the prevalence of gastrointestinal bleeding. If the NSAIDs need to be continued in older patients who have demonstrated evidence of peptic disease, then cotreatment with high dose $\mathrm{H}_{2}$ receptor antagonists or proton pump inhibitors (PPIs) is mandatory.

The present mainstays of treatment for peptic ulcer disease are the $\mathrm{H}_{2}$ receptor antagonists, PPIs, anti-H pylori treatment or cytoprotective agents such as sucralfate. Histamine receptor-blocking agents are still the most widely used agents for the treatment of peptic disease in elderly patients. These drugs work by direct suppression of gastric acid secretion - mainly nocturnal acid secretion. $\mathrm{H}_{2}$ receptor antagonists have an extremely low side effect profile, and several preparations can be administered only once or twice daily. Dosage adjustment is needed only in patients with renal or hepatic disease even in older patients. There have been no proven difference in the adverse reaction profiles of different $\mathrm{H}_{2}$ receptor antagonists in elderly patients. In particular, cimetidine causes no more confusion, depression, memory impairment or hallucinations than other $\mathrm{H}_{2}$ receptor antagonists. A meta-analysis of adverse reactions to cimetidine totalling over 600 patients showed no significant differences in side effects between patients treated with cimetidine or controls (65).

PPIs inhibit the gastric epithelial hydrogen/potassium ATPase pump, and are also very effective for short term therapy of peptic acid diseases. No side effects specifically applicable to elderly patients from the use of these drugs have been reported. Drug interactions with omeprazole include 
prolonged action of warfarin and phenytoin half-life (66). Secretory studies have shown that nocturnal acid secretion is more completely abolished with PPIs than with the $\mathrm{H}_{2}$ receptor antagonists.

Cytoprotective agents such as sucralfate are mostly effective against ulcers caused by stress or topical agents. They are believed to improve the mucosal barrier by stimulating mucosal PG synthesis. Sucralfate is difficult to administer in elderly patients because the drug needs to be taken four times daily, because of the large size of the pills and because of the side effect of constipation. Because of its aluminum content, elderly patients with renal failure should not use sucralfate for long term maintenance.

\section{REFERENCES}

1. McCarthy DM. Acid peptic disease in the elderly. Clin Geriatr Med 1991;7:231-54.

2. Sonnenberg A. Changes in physician visits for gastric and duodenal ulcer in the United States during 1958-1984 as shown by National Disease and Therapeutic Index (NDTI). Dig Dis Sci 1987;32:1-7.

3. Walt R, Katschinski B, Logan R, et al. Rising frequency of ulcer perforation in elderly people in the United Kingdom. Lancet 1986;i:489-92.

4. Tilvis, RS, Vuoristo M, Varis K. Changed profile of peptic ulcer disease in hospitalized patients during 1969-84 in Finland. Scand J Gastroenterol 1987;22:1238-44.

5. Baron JH. Lean body mass, gastric acid and peptic ulcer. Gut 1969;10:637-42.

6. Goldschmiedt M, Barnett CC, Schwarz BE, Karnes WE, Redfern JS, Feldman M. Effect of age on gastric acid secretion and serum gastrin concentrations in healthy men and women. Gastroenterology 1991;101:977-90.

7. Collen MJ, Abdulian JD, Chen YK. Age does not affect basal gastric acid secretion in normal subjects or in patients with acid peptic disease. Am J Gastroenterol 1994;89:712-6.

8. Katelaris PH, Seow F, Lin BPC, Napoli J, Ngu MC, Jones DB. Effect of age, Helicobacter pylori infection, and gastritis with atrophy on serum gastrin and gastric acid secretion in healthy men. Gut 1993;34:1032-7.

9. Feldman M, Cryer B, McArthur KE, Huet BA, Lee E. Effects of aging and gastritis on gastric acid and pepsin secretion in humans: A prospective study. Gastroenterology 1996;110:1043-52.

10. Khalil T, Singh P, Fujimura M, Townsend CM, Greeley GH, Thompson JC. Effect of aging on gastric acid secretion, serum gastrin and antral gastrin content in rats. Dig Dis Sci 1988;33:1544-8.

11. Waki S, Kinoshita Y, Wang H-Y, et al. Effect of aging on gastrin receptor gene expression in rat stomach. Peptides 1998;19:225-9.

12. Hurwitz A, Brady DA, Schaal E, Samloff IM, Dedon J, Ruhl CE. Gastric acidity in older adults. JAMA 1997;278:659-82.

13. Kinoshita Y, Kawanami C, Kishi K, Nakata H, Seino Y, Chiba T. Helicobacter pylori independent chronological change in gastric acid secretion in the Japanese. Gut 1997;41:452-8.

14. Lee M. Age-related changes in gastric mucosal bicarbonate secretion in rats. Age 1996;19:55-8.

15. Kim SW, Parekh D, Townsend CM, Thompson JC. Effects of aging on duodenal bicarbonate secretion. Ann Surg 1990;212:332-8.

16. Feldman M, Cryer B. Effects of age on gastric alkaline and nonparietal fluid secretion in humans. Gerontology 1998;44:222-7.

17. Lee M, Feldman M. Age-related changes in gastric mucosal glycoprotein synthesis in rats basally and in response to acute aspirin exposure. Gastroenterology 1993;63:104. (Abst A131)

18. Dial EJ, Lichtenberger LM. Development of gastric mucosal protection against acid in the rat. Role of corticosteroids and prostaglandins. Gastroenterology 1986;91:318-25.

19. Cryer B, Lee E, Feldman M. Factors influencing gastroduodenal mucosal prostaglandin concentrations: roles of smoking and aging. Ann Intern Med 1992;116:636-40.

20. Cryer B, Redfern JS, Goldschmeidt M, Lee E, Feldman M. Effect of aging on gastric and duodenal mucosal prostaglandin concentrations in humans. Gastroenterology 1992;102:1118-23.

\section{SUMMARY}

This review describes some of the physiological changes in the gastrointestinal tract of elderly patients and some of the peptic diseases encountered in this population. The diagnosis of peptic diseases and treatment require a careful and systematic approach by physicians. Because the clinical presentation of peptic diseases is usually obscure in elderly patients, prompt investigation is warranted in most cases. $\mathrm{H}_{2}$ receptor antagonists, PPIs and regimens to eradicate $\mathrm{H}$ pylori have a high success rate in the treatment of documented organic disease. Given the increase in life expectancy in our population, much consideration needs to be given to gastrointestinal problems in elderly patients in the next decade.

21. Pilotto A, Plebani M, Franceschi M, Vigneri S, Di Mario F, Valerio G. Effect of nizatidine on gastric mucosal prostaglandin concentration in elderly patients with antral erosive gastritis. Gastroenterology 1996;110:A230. (Abst)

22. Lee M, Feldman M. Age-related reductions in gastric mucosal prostaglandin levels increase susceptibility to aspirin-induced injury in rats. Gastroenterology 1994;107:1746-50.

23. Cryer B, Feldman M. Effects of very low dose daily, long-term aspirin therapy on gastric, duodenal, and rectal prostaglandin levels and on mucosal injury in healthy humans. Gastroenterology 1999;117:17-25.

24. Masuda Y, Ohno T, Uramoto H, Ishihara T. Effects of aging on gastric secretion and blood flow in rats. In: Garner A, O'Brien PE, eds. Mechanisms of Injury, Protection and Repair of the Upper Gastrointestinal Tract. Chichester: John Wiley \& Sons, 1990;309-17.

25. Lee M. Age-related changes in gastric blood flow in rats. Gerontology 1996;42:289-93.

26. Miyake H, Inaba N, Kato S, Takeuchi K. Increased susceptibility of rat gastric mucosa to ulcerogenic stimulation with aging. Dig Dis Sci 1996:41:339-45

27. O'Brien PE, Penney A, Lyons K, Comper W, Andrews F. Local influences on experimental ulcer healing. Digestion 1984;55(Suppl 2):31.

28. Tsukimi Y, Okabe S. Changes in gastric function and healing of chronic gastric ulcers in aged rats. Jpn J Pharmacol 1995;68:103-11.

29. Penney AG, Andrews FJ, O'Brien PE. Influence of age on natural and delayed healing of experimentally-induced gastric ulcers in rats. Dig Dis Sci 1996;41:1838-44.

30. Majumdar APN, Moshier JA, Arlow FL, Luk GD. Biochemical changes in the gastric mucosa after injury in young and aged rats. Biochim Biophys Acta 1989;992:35-40.

31. Lee M, Feldman M. Age-related reductions in gastric mucosal prostaglandin levels increase susceptibility to aspirin-induced injury in rats. Gastroenterology 1994;107:1746-50.

32. Uchida M, Misaki N, Kawano O, Yano S, Watanabe K. Change in formation of gastric lesions by aspirin during aging in rats. J Pharmacobiol 1990;13:493-6.

33. Pare WP, Vincent GP. Cimetidine and stress ulcer in aged rats. Physiol Behav 1984:33:305-8.

34. Goldstein R, Wozniak DF. Effect of age, food deprivation and stress on gastric erosions in the rat. Physiol Behav 1979;23:1011-5.

35. Majumdar APN, Edgerton EA, Arlow FL. Gastric mucosal tyrosine kinase activity during aging and its relationship to cell proliferation. Biochim Biophys Acta 1988;965:97-105.

36. Majumdar APN, Moshier JA, Arlow FL, Luk GD. Biochemical changes in the gastric mucosa after injury in young and aged rats. Biochim Biophys Acta 1989;992:35-40.

37. Majumdar APN, Tureaud J, Relan NK, et al. Increased expression of pp60c-src in gastric mucosa of aged rats. Gerontology 1994:49:B110-6.

38. Lei L, Turner JR, Ahmed YY, et al. Differential expression of EGFR during early reparative phase of the gastric mucosa between young and aged rats. Am J Physiol 1998;275:G943-50.

39. Relan NK, Fligiel SEG, Dutta S, Tureaud J, Chauhan DP, Majumdar APN. Induction of EGF-receptor tyrosine kinase during early reparative phase of gastric mucosa and effects of aging. Lab Invest 1995;73:717-26. 
40. Fligiel SEG, Relan NK, Dutta S, Tureaud J, Hatfield J, Majumdar APN. Aging diminishes gastric mucosal regeneration: Relationship to tyrosine kinases. Lab Invest 1994;70:764-74

41. Majumdar APN, Edgerton EA, Arlow FL. Gastric mucosal tyrosine kinase activity during aging and its relationship to cell proliferation. Biochim Biophys Acta 1998;965:97-105.

42. Attilasoy EO, Holt PR. Gastrointestinal proliferation and aging. J Gerontol 1993;48:A43-9.

43. Majumdar APN. Regulation of gastric mucosal proliferation during advancing age. In: Vellas B, Albarede JL, eds. Facts and Research in Gerontology. New York: Springer Publications, 1993;27-34.

44. Grishaw EK, Ott DJ, Frederick MG, Gelfand MG, Chen MYM. Functional abnormalities of the esophagus: a prospective analysis of radiographic findings relative to age and symptoms. AJR Am J Roentgenol 1996;167:719-23.

45. Xie P, Ren J, Bardan E, Mittal RK, Sui Z, Shaker R. Frequency of gastroesphogeal reflux events induced by pharyngeal water stimulation in young and elderly subjects. Am J Physiol 1997;272:G233-7.

46. Moore JG, Tweedy C, Christian PE. Effect of age on gastric emptying of liquid and solid meals in man. Dig Dis Sci 1983;28:340-5.

47. Samly AH. Clinical manifestations of disease in the elderly. Med Clin North Am 1987;67:333-44.

48. Phillips SL, Burns G. Acute abdominal disease in the aged. Med Clin North Am 1988;72:1213-24.

49. Sodeman W, Saladin T, Boyd W. Geriatric Gastroenterology. Philadelphia: WB Saunders Co, 1989.

50. Freston MS, Freston JW. Peptic ulcers in the elderly: unique features and management. Geriatrics 1980;45:39-45.

51. Antler AS, Pitchumoni CS, Thomas E. Gastrointestinal bleeding in the elderly: morbidity, mortality and cause. Am J Surg 1981;142:271-6.

52. Kurata JH, Nogawa AN. Meta-analysis of risk factors for peptic ulcer. J Clin Gastroenterol 1997;24:2-17.

53. Strange S. Giant innocent gastric ulcer in the elderly. Gerontol Clin 1963;5:171-89.
54. Samal SC, Ramakrishna BS. Gastrointestinal problems in the elderly. Ind J Med Res 1997;106:295-311.

55. Klauser AG, Schindlbeck NE, Muller-Lissiner SA. Symptoms of gastroesophageal reflux disease. Lancet 1990;ii:205-8.

56. Raiha I, Hietanen E, Sourander L. Symptoms of gastroesophageal reflux disease in elderly people. Age Ageing 1991;20:365-70.

57. Friedman LS, Castell DO. Esophageal Diseases in the Elderly. The Esophagus. Boston: Little Brown \& Co, 1992.

58. Jones DM, Eldridge J, Fox AJ. Antibody to the gastric campylobacterlike organism ('Campylobactor pyloridis') - clinical correlation and distribution in the normal population. J Med Microbiol 1986;22:57-62.

59. Graham DY, Adam E, Reddy GT, et al. Seroepidemiology of Helicobacter pylori infection in India: comparison of developing and developed countries. Dig Dis Sci 1991;36:1084-8.

60. O'Riordan TG, Tobin A, O'Morian C. Helicobacter pylori infection in elderly dyspeptic patients. Age Ageing 1991;20:189-92.

61. Abdalla AM, Sordillo EM, Hanzely Z, et al. Insensitivity of the CLO test for $\mathrm{H}$ pylori especially in the elderly. Gastroenterology 1998;115:243-50.

62. Cutler AF, Havstad S, Blaser MJ, Perez-Perez GI, Schubert TT. Accuracy of invasive and noninvasive tests to diagnose $H$ pylori infection. Gastroenterology 1995;109:136-41.

63. Cooper BT, Neumann CS. Upper gastrointestinal endoscopy in patients aged 80 years or more. Age Ageing 1986;15:343-9.

64. Dooley CP, Weiner JM, Larson AW. Endoscopy or radiography? The patient's choice. A prospective comparative survey of patient acceptability of upper gastrointestinal endoscopy and radiography. Am J Med 1985;80:203-7.

65. Richter JM, Colditz GA, Huse M. Cimetidine and adverse reactions: A meta-analysis of randomized clinical trials of short term therapy. Am J Med 1989;87:278-84.

66. Gugler R, Jensen JC. Omeprazole inhibits oxidative drug metabolism. studies with diazepam and phenytoin in vivo and 7-ethoxycoumarin in vitro. Gastroenterology 1985;89:1235-41. 


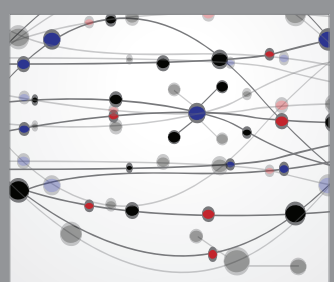

The Scientific World Journal
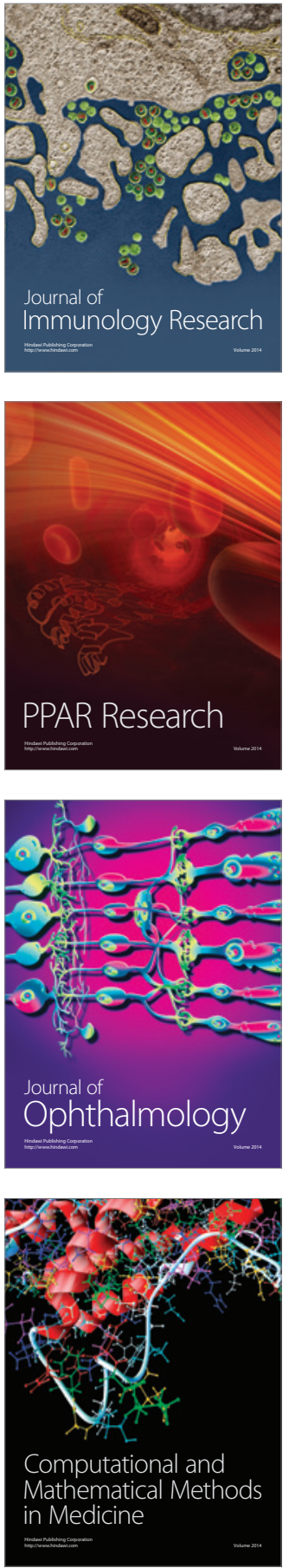

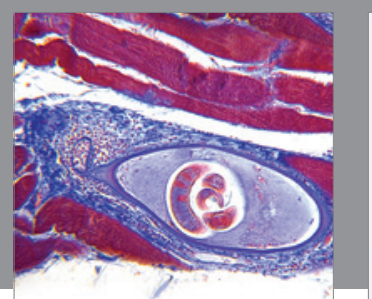

Gastroenterology Research and Practice

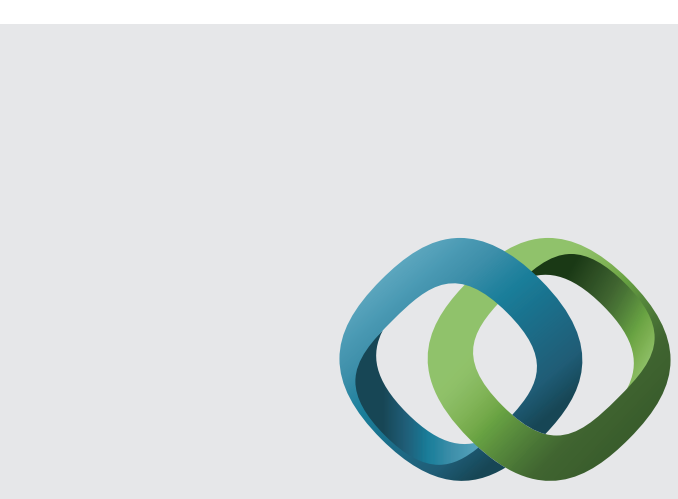

\section{Hindawi}

Submit your manuscripts at

http://www.hindawi.com
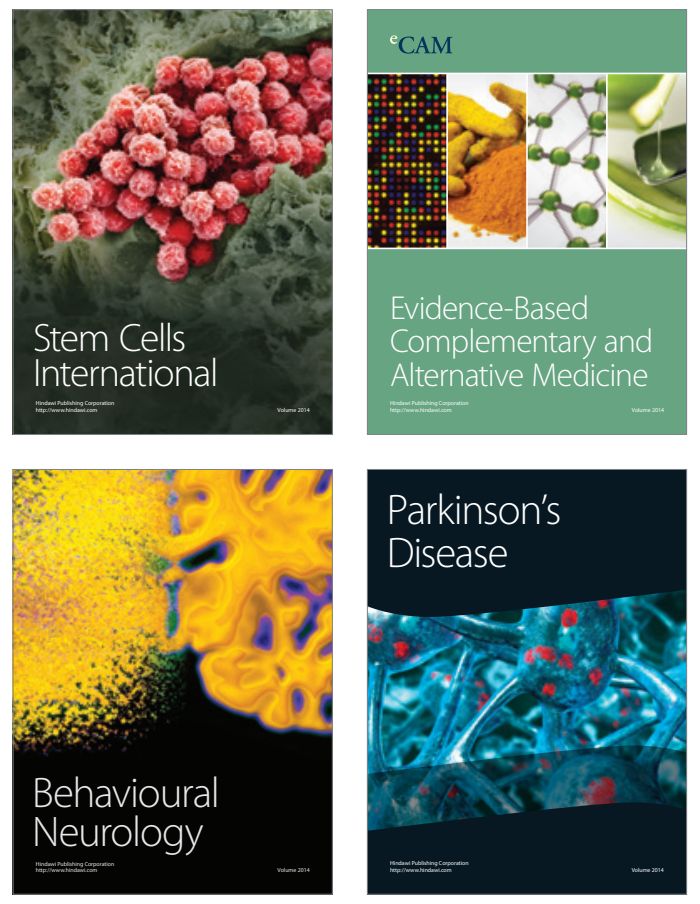
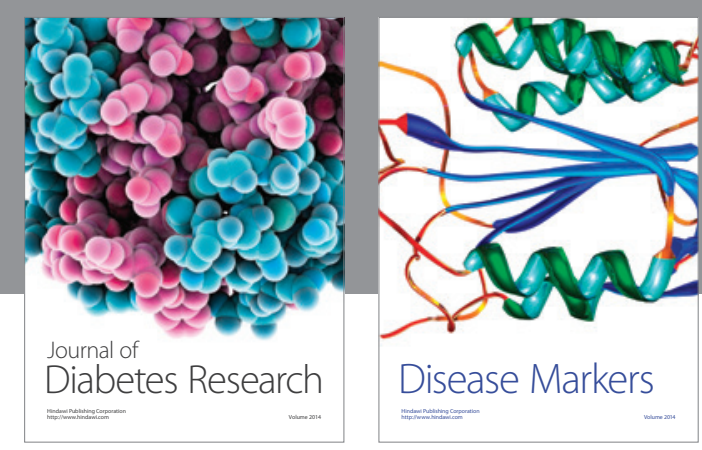

Disease Markers
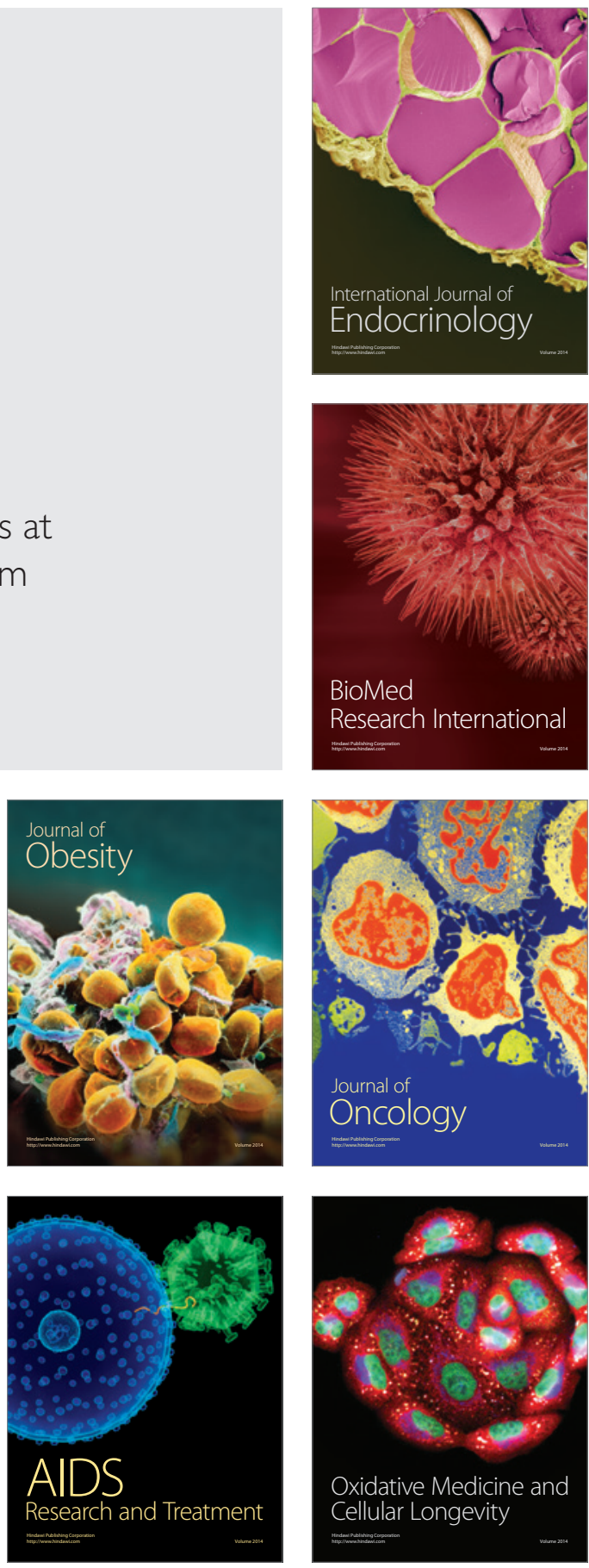